\title{
DEVELOPING A PROGRAM FOR SPECIALIST UROLOGICAL CARE IN THE RURAL HOSPITALS OF BANGLADESH
}

\author{
MA SALAM
}

Founder president of Urology and Transplantation Foundation of Bangladesh, 57/9 Panthapath Avenue, Dhaka, Bamgladesh

Bangladesh J. Urol. 2017; 20(2): 99-101

The growth of large metropolitan areas across Bangladesh has fostered the need to provide tertiary care to patients outside of the traditional medical colleges and University-affiliated hospitals. Subspecialty urology care at centers of excellence in the University hospital includes Urological Oncology, Renal Transplantation, Pediatric urology, and Female Urology and Reproductive Urology. The objective of this concept paper is to develop safe, sustainable, cost-effective care closer to home enabling appropriate investigations and outpatient treatment carried out in community settings at the door step by appropriate set up and performed by appropriately skilled personnel.

The 'Care Closer to Home' plan intended to substitute community for hospital care by providing specialist care in the community rather than simply moving existing specialists into community settings $[1,2]$. This may be accomplished by making greater use of motivated and trained medical officers or GPs, nurses and other staffs. It is possible to implement this idea through the enhancing resources and provision of diagnostic and treatment facilities in community hospitals like upazilla hospitals or even a private clinic [3,4].

An objective to provide an enhanced range of services, giving fast access to an expert service, reducing the need for patient travel to hospitals and removing barriers between primary and secondary care [4]. The common objective to develop safe, sustainable, cost-effective care closer to home enabling appropriate investigations and outpatient treatment carried out in community settings by ensuring services are delivered 'in the right setting, with the right equipment and performed by appropriately skilled personnel'[5,6].

Conversion of a small hospital in village or upazilla health complex in to smart community urology clinic.

To meet the objective, the community centers professionals (medical officers and nurses)to be are prepared to take on basic urological evaluation and basic investigations procedures in the community centers. Examples may be noninvasive test like Urine test, blood test, uroflowmetry and abdominal ultrasound. In most of the community centers these tests are done with confidence of Bangladesh. These peoples may be trained to be enabling to meet the urological requirements.

\section{Urological armamentarium}

On the top of the existing equipment's a colorimeter or an semi auto analyzer will be required. An uroflowmeter may need to be installed but it is not expensive tool. Ultrasound machine may be available in the hospital if not available it may be procured easily from the local market as the price today is affordable to almost all patients. A portable flexible Cystoscope may be the solution as the visiting urology team may carry it to the center from the referral center.

\section{Connection with the regional Urology canter:}

The center may be connected to a regional urology center a medical college. Once a week an urologist team consist of an urologist accompanied by urology residents may visit the center and see all the selected cases of urology prepared by the medical doctors and staffs of the centers. Appropriate cases may be referred to his own center or to an advanced center. All other cases may be advised and treat at their door steps. I am not recommending surgical intervention at this stage. But if the community urology clinic runs about a year or so, a hematuria clinic may run well with the existing tool with the addition of a portable flexi cystoscope may be carried by the team from the regional center.

\section{Services may be provided}

The periodical urological services at the nearest health center may be own by private or Government, this 'Shifting Care Closer to Home [7] may include many common urological issues for men, women and children's. In Asian population the later two groups of

Correspondences: Professor MA Salam, Founder President of Urology and Transplantation Foundation of Bangladesh, 57/9 Panthapath Avenue, Dhaka, Bamgladesh 
patients may not have an access to a specialist care in a specialized center. Urinary infections, LUTS, hematuria, erectile dysfunction (ED), female voiding difficulties, BPH, follow up of post operative cases and cancer follow-up can easily be performed in the rural setting at the door step of the patients.

This regular services in the urology satellite clinics will empower the local doctors GP, Nurses and other staffs to perform non invasive test to reach a reasonably correct diagnosis and correct referral with time.

\section{UK Experiences}

Such kind of training program for General Practitioners performed in UK was evaluated. The ability of the GP to manage common urological conditions and ability referral to urologists was studied The survey showed that less than half of GPs were 'happy to manage' common urology problems such as ED (49\%), female voiding difficulties (45\%) and BPH (43\%). Only a tiny minority felt able to manage patients with haematuria $(2 \%)$, female incontinence $(16 \%)$ and family planning (28\%). Hence, a large majority of GPs are referring these patients to hospital-based urologists for management (Fig. 1).

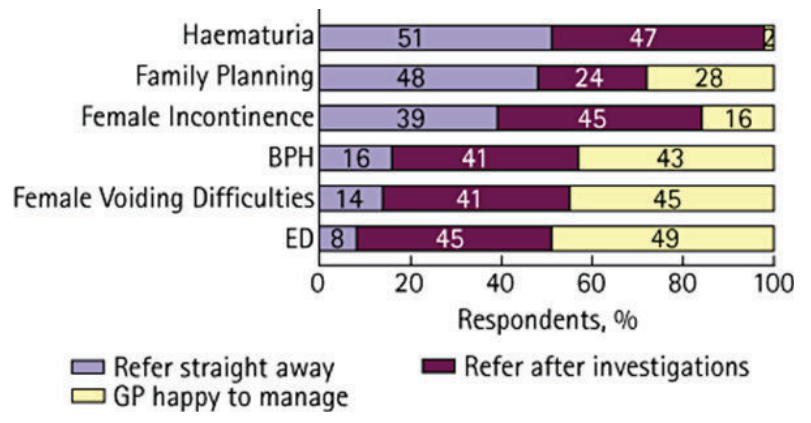

Fig.-1

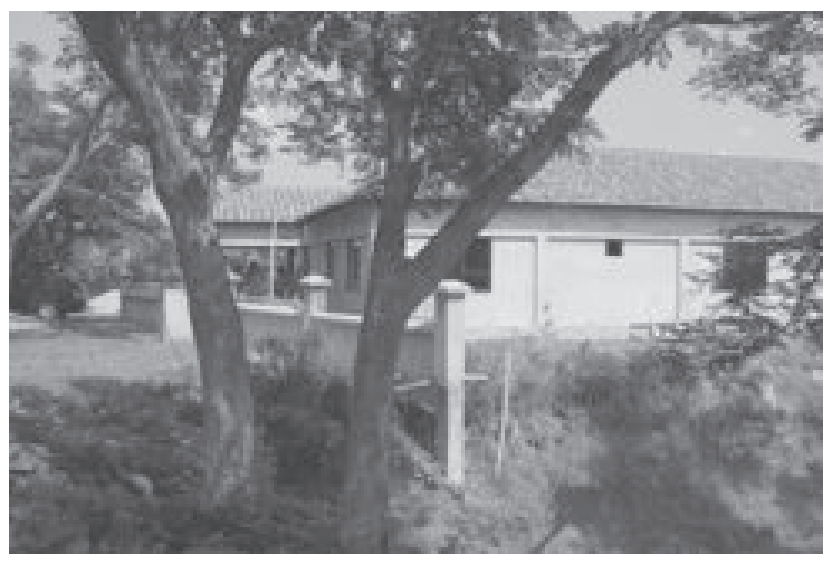

A large proportion of GPs refer patients with haematuria $(51 \%)$, family planning $(48 \%)$ and female incontinence (39\%) immediately without any investigations while this was less evident for patients with $\mathrm{BPH}(16 \%)$, female voiding difficulties (14\%) and ED (8\%)[3].

\section{Procedures/investigations performed by GP}

Overall, very few GPs (range 93-100\%) carry out urological procedures or interpret urological investigations (Fig. 2), apart from DRE, which was performed regularly by $62 \%$ of GPs. Importantly, almost a fifth (19\%) of GPs never perform DRE for urological conditions, which may be of potential clinical importance[3,4].

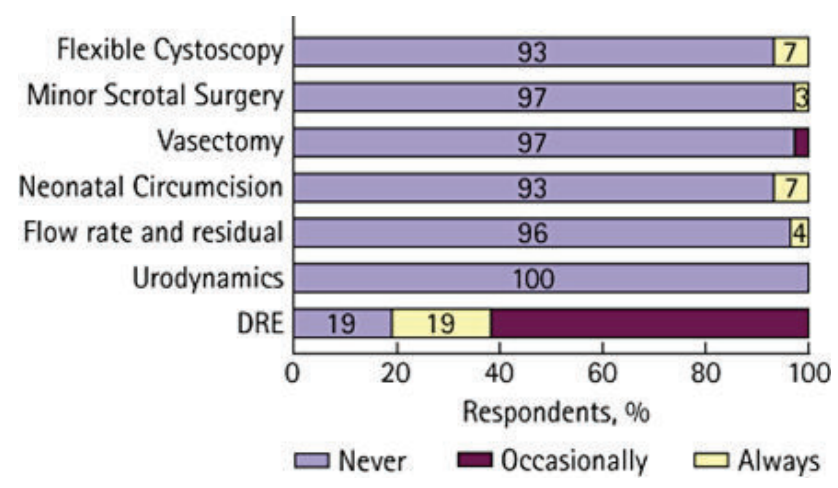

Fig.-2

\section{The cost-benefit analysis}

The cost-benefit analysis for the 'Care Closer to Home' plan would require training for doctors, nurses and allied health professionals and ease of access to the urology services against patient satisfaction [8]. It will be important for urologists to work with primary care practitioners to set minimum standards to be achieved

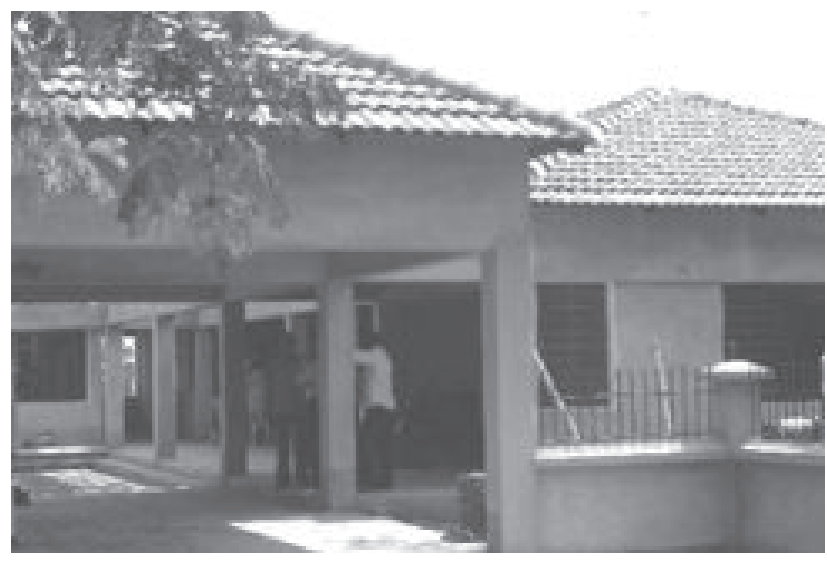


by that undertaking urology specialist work in the community setting and then assess competency of community-based providers to deliver. Necessary educational interventions should be introduced before changing services. Service quality should be audited to agreed standards (by interested parties in hospital and primary care) before and after implementation.

\section{Conclusion}

Bangladesh is an example of a heavily populated developing country. The financial status of most people is poor and most of them lived in the villages. Many sick people can rarely have access to the specialist care. To overcome tis scenario this proposal if can be implemented a large number of rural peoples will be under urologist care. Here the government and NGO like WHO, UNICEF etc would have to work together. We have established such a center at Sondah, Santhia, Pabna, Bangladesh become a successful project on entirely personal initiative. We may look forwards to see many more community hispitals with this ideas. Infact all the community hospitals may be linked to the regional specialist center to expand the 'specialist services to the door steps' in Banglasedh.

\section{References}

1. Department of Health. Shifting Care Closer to Home Demonstration Sites - report of the speciality subgroups (2007). Available at: http:// www.dh.gov.uk/prod_consum_dh/groups/ dh_digitalassets/@dh/@en/documents/ digitalasset/dh_079800.pdf. Accessed August 2010

2. Department of Health. Our health, our care, our say: a new direction for community services (2006). Available at: http://www.dh.gov.uk/prod_consum_ dh/groups/dh_digitalassets/@dh/@en/documents /digitalasset/dh_4127459.pdf. Accessed August 2010

3. NHS Confederation. Ideas from Darzi: polyclinics (2008). Available at: http://www.nhsconfed.org/ Publications/Documents/Ideas $\% 20$ from $\%$ 20Darzi\%20Polyclinics.pdf. Accessed August 2010

4. Department of Health. Healthcare for London. A framework for action (2007). Available at: http:// www.healthcareforlondon.nhs.uk/assets/ Publications/A-Framework-for-Action/aFramework ForAction.pdf. Accessed August 2010

5. Department of Health. The NHS Plan: a plan for investment, a plan for reform (2000). Available at:http://www.dh.gov.uk/prod_consum_dh/groups/ dh_digitalassets/@dh/@en/@ps/documents/ digitalasset/dh_118522.pdf. Accessed August 2010

6. Department of Health. Shifting the balance of power: the next steps (2002). Available at: http:// www.dh.gov.uk/prod_consum_dh/groups/ dh_digitalassets/@dh/@en/documents/ digitalasset/dh_4073554.pdf. Accessed August 2010

7. Department of Health. Shifting Care Closer to Home Demonstration Sites - report of the speciality subgroups (2007). Available at: http:// www.dh.gov.uk/prod_consum_dh/groups/ dh_digitalassets/@dh/@en/documents/ digitalasset/dh_079800.pdf. Accessed August 2010

8. Kernick DP. Developing intermediate care provided by general practitioners with a special interest: the economic perspective. Br J Gen Pract 2003; 53: 553-6 PubMed | Web of Science ${ }^{\circledR}$ Times Cited: 8 